\title{
Computer Emulations to Support Training in Automation
}

\author{
Manuel E. Macías and Ernesto D. Guridi \\ Electrical and Computing Engineering, ITESM Campus Monterrey \\ Monterrey N. L., \\ México
}

\section{Introduction}

With the main objectives of complementing the process rather than eliminating the real experience from the student, and making it more efficient, the Electrical and Computing Engineering Department at ITESM Campus Monterrey has been developing and using, for the last 3 years, computer emulations of real industrial processes at the Tele-Engineering Lab. The obtained results have shown that the students perform much better than in a traditional laboratory session.

An Emulation is a computer model that mimics the operation of a real or proposed system. With Emulations, different solutions can be implemented and tested without the availability of the real system. Emulations are goal directed experimentation using dynamic models. Hence, it provides repeatable experimentation opportunities under controlled and extreme conditions [1-3]; students are able to experience several possible problems before facing them in real systems. As it is expected and even desired, students make mistakes while programming. A serious mistake on a computer screen is infinitely preferable to a mistake in a real system.

Another important aspect to consider is that every single student has his/her own learning method and also his own rhythm. One cannot expect to get the same results, in the same manner, from two different students $[4,5]$. It is important to keep in mind that there may be several solutions for the same assignment and that the complexity between different solutions may vary. When students are restricted to obtain a solution in a certain period of time within a laboratory session, their chances to reach a correct solution could be limited. By handing the emulations to the students, the laboratory concept is extended. The students are then able to program, test, and debug their PLC programs without being restricted to a scheduled laboratory session. The laboratory, is therefore, virtually always available.

\section{Main advantages}

The aims of using emulations are, respectively, gaining insight, performance prediction, and finding the appropriate input values for a desired behavior [3].

Therefore, Emulations are useful to support education and provide training in areas where dynamic systems are involved $[1,2,5,6]$. Concerning the Industrial Automation field, there are several advantages in having an emulated system:

Source: Programmable Logic Controller, Book edited by: Luiz Affonso Guedes,

ISBN 978-953-7619-63-3, pp. 170, January 2010, INTECH, Croatia, downloaded from SCIYO.COM 
- Costs: One of the most noticeable benefits is the cost. Many universities cannot afford enough appropriate equipment, such as scaled models of industrial processes that help them to develop practical skills on the students. With the use of Emulations, universities could acquire a single model to equip their laboratories or even, if their budget is not enough, make the students practice by the only use of Emulations.

- Debugging: Programming errors discovered using Emulations would not be as costly, because the errors discovered during the testing process would not damage the equipment. The use of the emulations to debug the student's program highly reduces the possibilities to commit errors in the real system.

- Availability: In most cases, only one actual system would be available and students would only be able to test programs on the system one at a time, making the process inefficient. This is not the case with the Emulation, where students can be testing programs simultaneously, because of the fact that each student could have his own virtual duplicate of the system at his own computer.

- Animation: Using animation to visualize system behavior greatly increases the ability to spot problems and certainly enhances students' learning [2, 7]. The process behaves accordingly to the student written code.

- Diversity: With diverse kinds of processes, the students can practice different programming techniques, enriching their qualifications. A University could have a library of emulated models, containing processes with different complexities, each of them to be used in homeworks, projects, or tests.

- Versatility: With Emulations you can quickly try out your ideas. Any promising correct solution is either accepted or dismissed much faster.

- Overall understanding: Students have a better overall understanding of a new system or process when they work with its Emulation. Sometimes sensors in real systems are not accessible or visible to the student. In the Emulation, the location of each sensor is clearly specified.

- Handling of Time. An often named advantage of emulations is that they (virtually) instantly show the results of the students' decision. Furthermore, the "expansion of time" is also a major characteristic of emulators; users have more time than in reality to contemplate a complex situation and to make a decision. Emulators with adjustable time frames can be used [4].

\section{Process Emulations' characteristics}

Although we know that Emulations are not always a perfect match of the physical system behavior, it is attempted with them to virtually duplicate a real system.

As a matter of fact, there are certain process characteristics that, because of their rare or occasional existence (such as hardware failures, external disturbances, or even a behavioral modification), cannot be exactly replicated.

Therefore, Emulations should be as similar as possible to the actual process. The operational characteristics of the sensors and the actuators must be preserved, such as the signals provided by the sensors and the required signals to activate the actuators. Also, it is desired that every sensor can be manipulated with a mouse click. This allows the user to activate the sensors at any time, the same way it happens in the real system using an external object. Through a process of abstraction, we select those details that are most critical to characterize the operation of the system. The degree of detail required in a model depends on the nature of the system itself. 
An important aspect to consider when developing Emulations is the appropriate selection of the view to be used, in order to have a complete visualization of the process. It is desired that any possible programming error can be detected. Also, even when it is almost impossible to predict all the probable errors that could appear while programming, the behavior of the Emulation before common error situations can be established. For instance, if an actuator used to move an object is not deactivated when the object has reached its physical limit, in the real system the actuator will be forced and the object will not move beyond this limit; in the Emulation the object will continue moving off the screen, helping the student to detect his error.

\subsection{Real processes: scale models}

At the Tele-Engineering Lab several scale models of industrial processes are currently being used, such as: Transport and Sorting Lines, Process Lines with Machine Tools and 3-Axis Portals, from the Staudinger $\mathrm{GmbH}$ company.

The Transport and Sorting Line model, shown in Figure 1, simulates a handling device to allocate part loads from a store register to various discharge stations, as used, for example, in a parcel distributor's logistics.

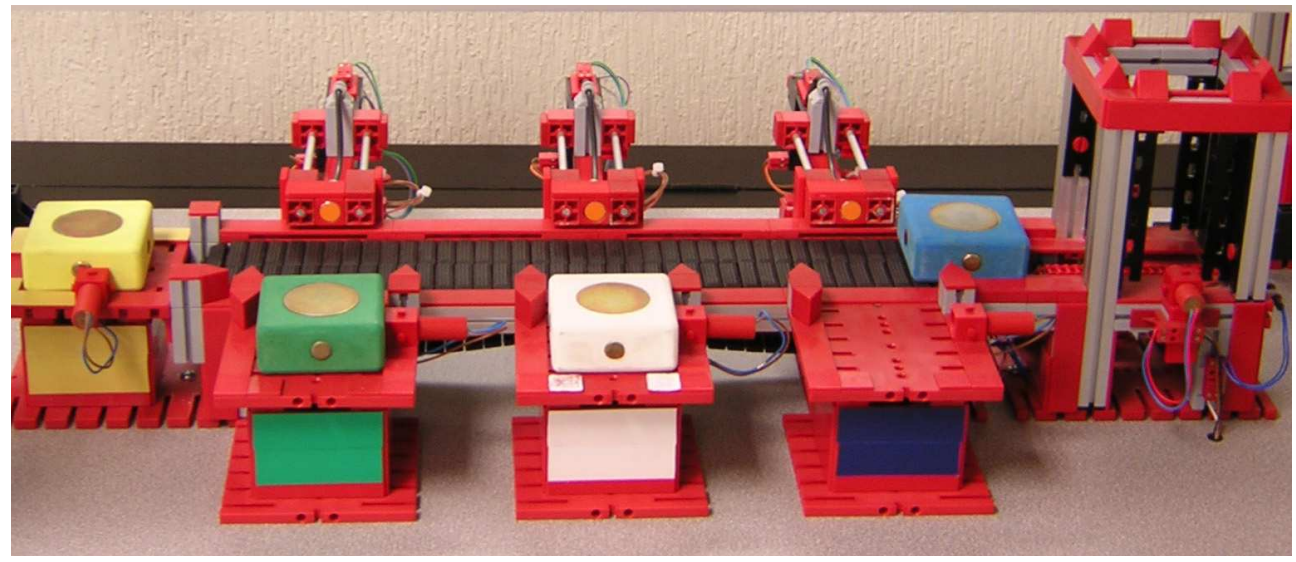

Fig. 1. Scale Model Transport and Sorting Line

The Transport and Sorting Line consists of a storage register with an integrated conveyor chain, a conveyor belt, three pushers, and four discharge stations. The scale model shows parcels being withdrawn from the store register, being recognized at an identification unit, getting transported to the corresponding discharge station by a conveyor belt, and finally being poked from the conveyor belt to the discharge station by a pusher.

\subsection{Emulated processes}

Each of the real models used at the Lab has been already emulated. The Emulations of the models were created using LabVIEW from National Instrument as the development tool, since it offers a graphical interface to the user, who can easily operate it.

The emulated model of the Transport and Sorting Line is shown in Figure 2. As it can be seen, a top view was selected to emulate this system. The reason of this is that this view 
provides a complete visualization of the process. Also, the location of each Sensor is clearly identified.

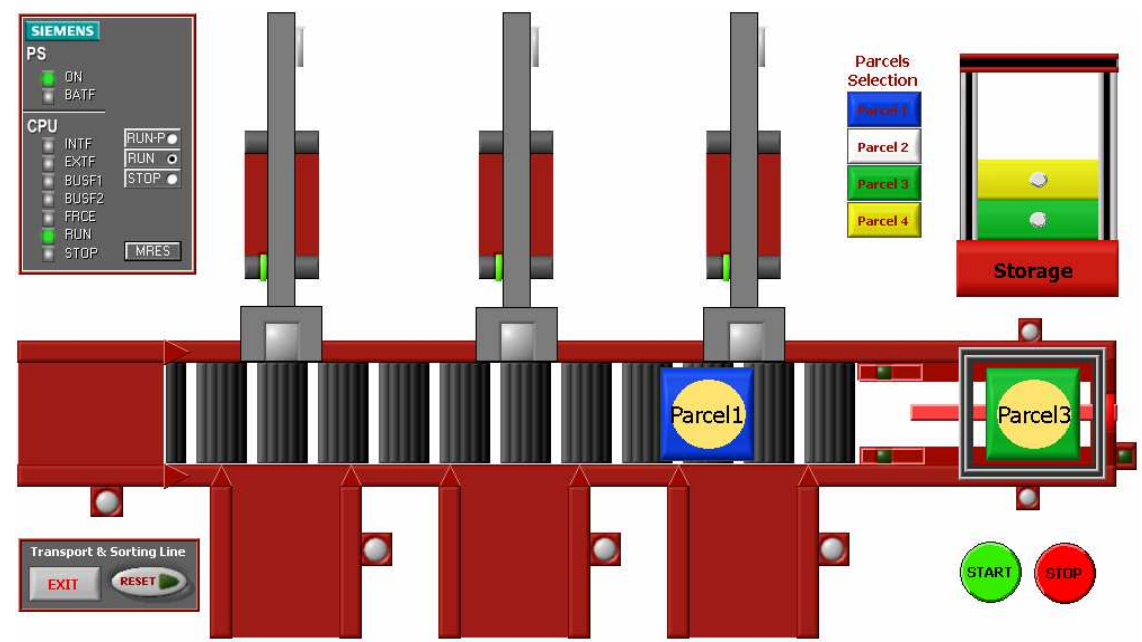

Fig. 2. Emulated Model Transport and Sorting Line

The scale model of a Process Line with Machine tool and its corresponding Emulation are shown in Figures 3 and 4, respectively. The process line consists of a turret drilling machine, three conveyor belts, a slewing table with conveyor chains and an automated lay-in-unit. The scale model shows a workpiece being provided at the lay-in-unit, then being brought onto the conveyance by a pusher, getting transported to the process cell, getting machined" in several steps and finally being brought out to a discharge station by using the slewing table.

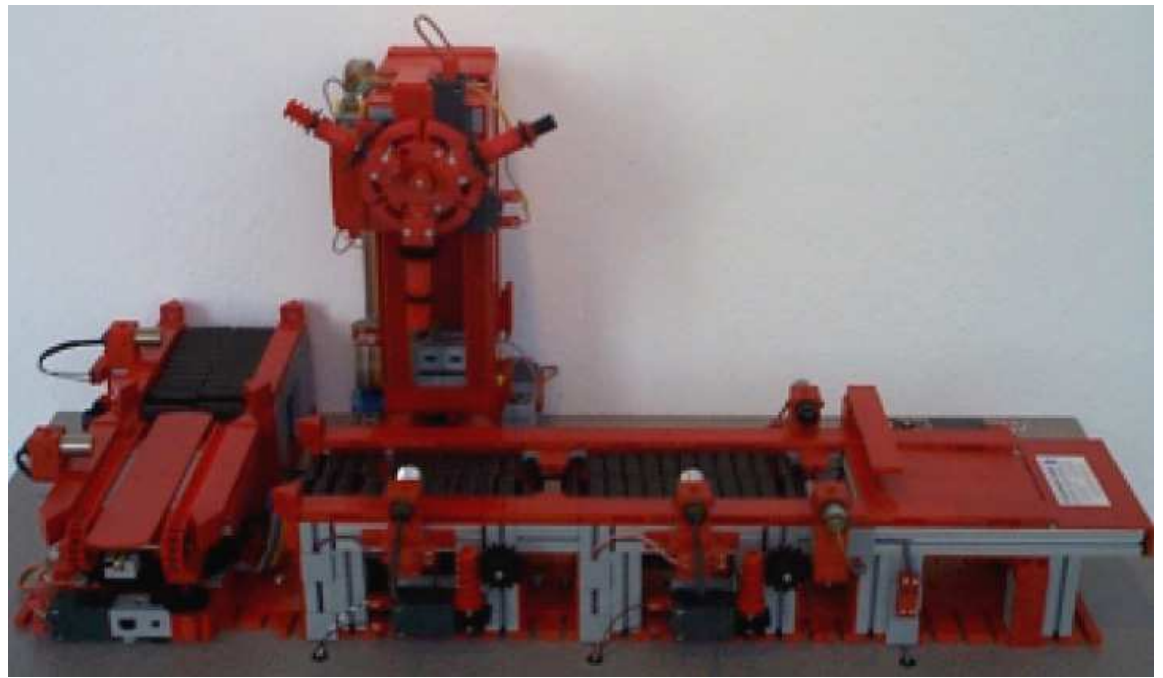

Fig. 3. Scale Model Process Line with Machine Tool 


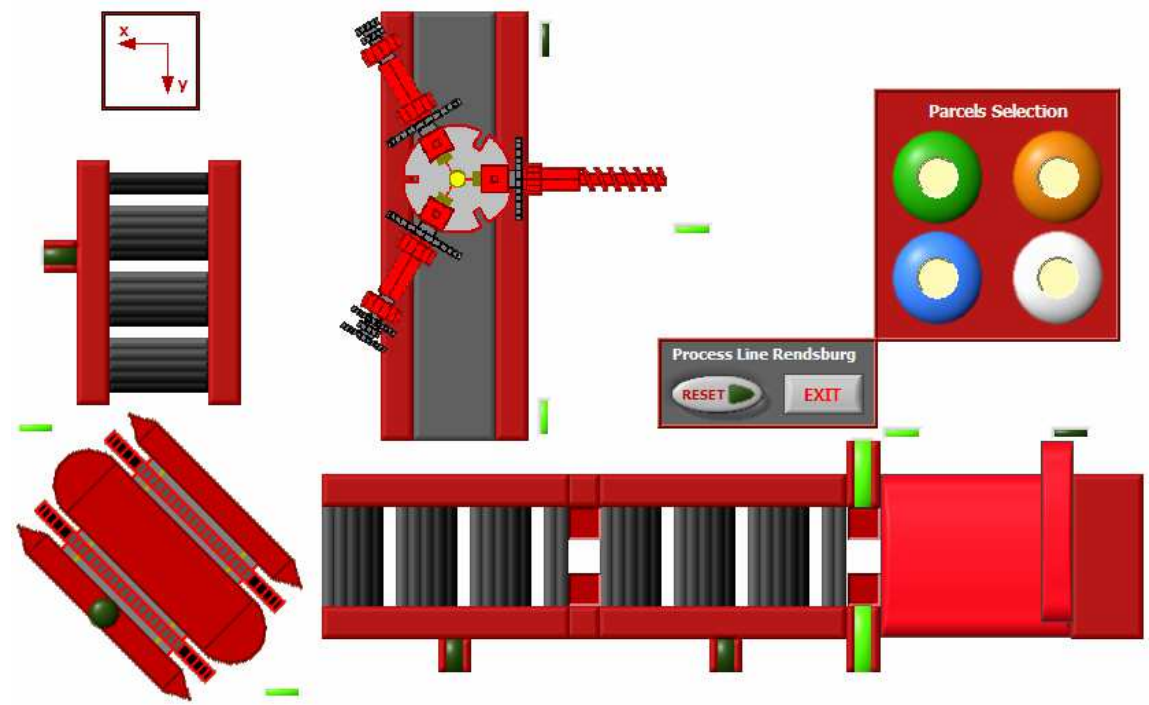

Fig. 4. Emulated Model Process Line with Machine Tool

At the present, a diverse library of Third-Dimension (3D) Emulations is being developed. 3D Emulations offer, as it could be expected, more characteristics than the ones in Two Dimensions (2D). In a 3D visualization it is possible to get immersed into the process and actually adapt the view to observe specific tasks or circumstances occurring during the process. On a 3D environment the student can zoom, rotate, or scroll the process at will (see Figure 5).

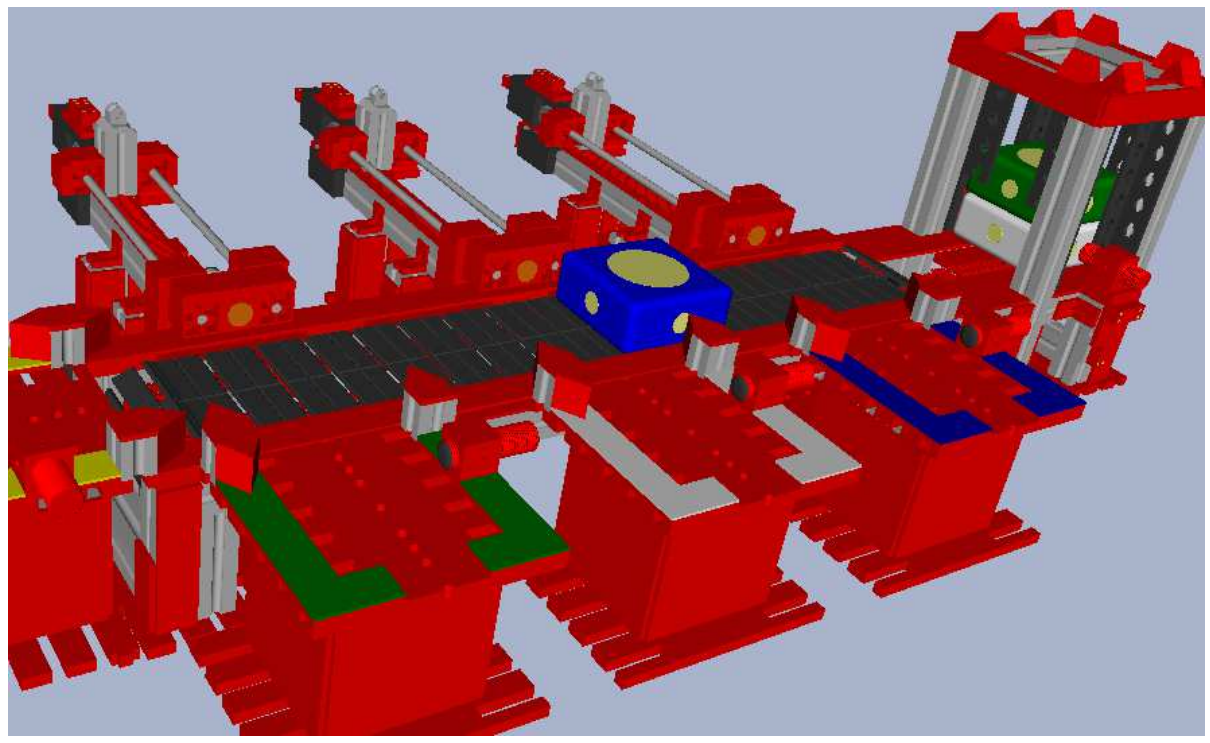

Fig. 5. Transport and Sorting Line Emulated on a 3D Environment 
Taking advantage of the 3D visualization, students can observe the process from perspectives that most of the times are not available on real systems (see Figure 6).

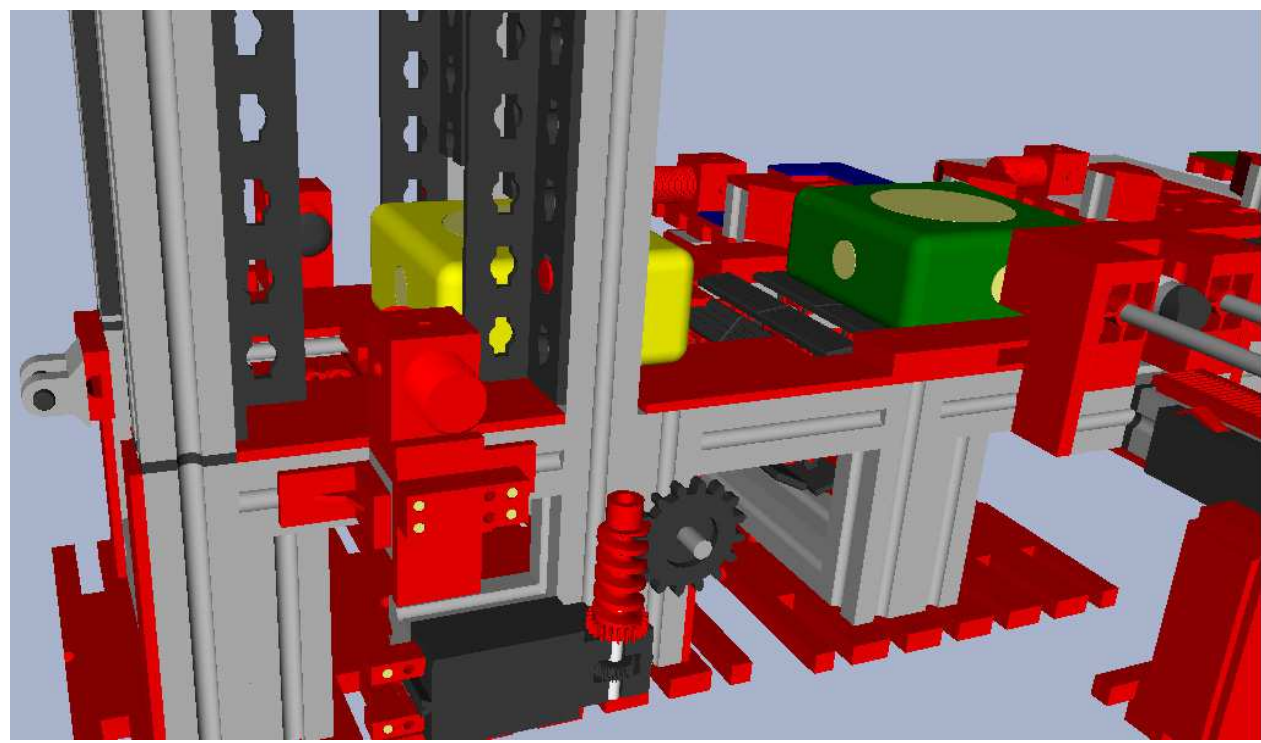

Fig. 6. Different Perspective on the 3D Environment

\section{Use of the Emulations}

Before the development of the Emulations, the students had to solve the exercises and the Automation projects at the laboratory, and only within the laboratory sessions. This caused that pretty often, students could not finish the exercises on time, since the automation tasks normally require a considerable amount of tests in order to get to a correct solution. If the students wanted to prepare the exercises before the laboratory sessions, they could only sketch on paper a possible solution and they did not have the possibility to validate it. Most of the times, the proposed solution contained programming errors that needed to be debugged and several tests were required.

This fact forced that either the exercises had to be designed in such way that they could be solved in a laboratory session, reducing their complexity, or that the same exercise had to be solved using different sessions. In both cases, the process was inefficient and the desired abilities were not developed in the students as desired.

This is not the case when using Emulations. By handing the emulations to the students, they do not have to wait until the next laboratory session in order to validate their proposed solution. Therefore, the students have more flexibility to test and debug their PLC programs, because they can work wherever they want and without being restricted to a schedule.

For this purpose, the students receive the tools required to solve the different assignments outside of the laboratory session: the stand-alone executable version of the determined Emulation that they need to automate and the Student Version of the development Software, Step7, from Siemens, which also includes the computer simulation of the Siemens controllers, S7-PLCSIM. 
Students are given an automation task to solve, in which they have to make an analysis of the process in order to gain ideas that approach them to a correct solution. The implementation of their proposed solution may be unsuccessful and a redesign will be required. This leads the students to try their solutions on the Emulation several times in order to get to the final one. If the laboratory session comes to an end before they have reached a correct solution for the task, they can continue working outside of the laboratory. At the next laboratory session, the instructor tests the PLC program in the Emulation and only when the program runs completely out of errors, the students are asked to test it at the real system.

\section{Development tool}

The software used to develop the Emulations is LabVIEW, from National Instruments. This development tool offers important advantages in comparison to similar simulation software, such as SIMIT, from Siemens, DELMIA, from Dassault Systems, COSIMIR, from Festo, and SPS-VISU, from MHJ-Software, among others.

Whereas some are very complex and expensive tools, others are cheaper but not so flexible. None of them allow a massive distribution of the developed models, since a license needs to be purchased; even if it is only desired to use already developed Emulations.

The main advantages of our development using LabVIEW to emulate processes are:

- Distribution. Once an Emulation has been developed, it can be distributed in a limitless way and completely free of charge to the students. The students just need to download the LabVIEW-Runtime from the Internet, which can be installed without the need of a license.

- Portability. Emulations can be used in computers running different operating systems. The development tool runs in diverse platforms such as: Windows, Mac OS, Solaris and Linux.

- ActiveX Support. LabVIEW supports the ActiveX functions. Although the Emulations were developed to be used with Siemens software, they can be easily adapted to work with software from different companies that support the ActiveX Technology.

- OPC Support. LabVIEW also supports the OPC Technology, which offers an open protocol to exchange data between applications from different companies. In the case of the Emulations, the OPC Technology can be used to control the Emulations using real PLC's from different providers. When the Emulations are controlled by real PLC's, the students can build up and then validate the required hardware configuration of the PLC, complementing the entire process.

\section{Developed libraries}

The connection between the Emulations and the simulated or the real PLC is achieved with a set of self developed libraries, which makes use of LabVIEW's ActiveX Technology support. Depending on the desired connection (whether with a simulated or with a real PLC), an appropriate ActiveX Control is used.

Besides, when working with real Siemens Controllers, the libraries allow the connection through almost all the PLC supported industrial networks, such as MPI, PROFIBUS, and Industrial Ethernet. 
The libraries have been divided in 5 groups accordingly to the LabVIEW's programming standard: configuration, open, write, read, and close section. Furthermore, the error codes have been analyzed and prepared in such a way that, if a problem occurs, the user can easily find it out.

The libraries also take advantage of the polymorphic property, in order to write or read different data types with the same write or read function.

Figure 7 shows a typical connection with PLCSim. One can observe the way to write and to read an entire input and output byte, respectively.

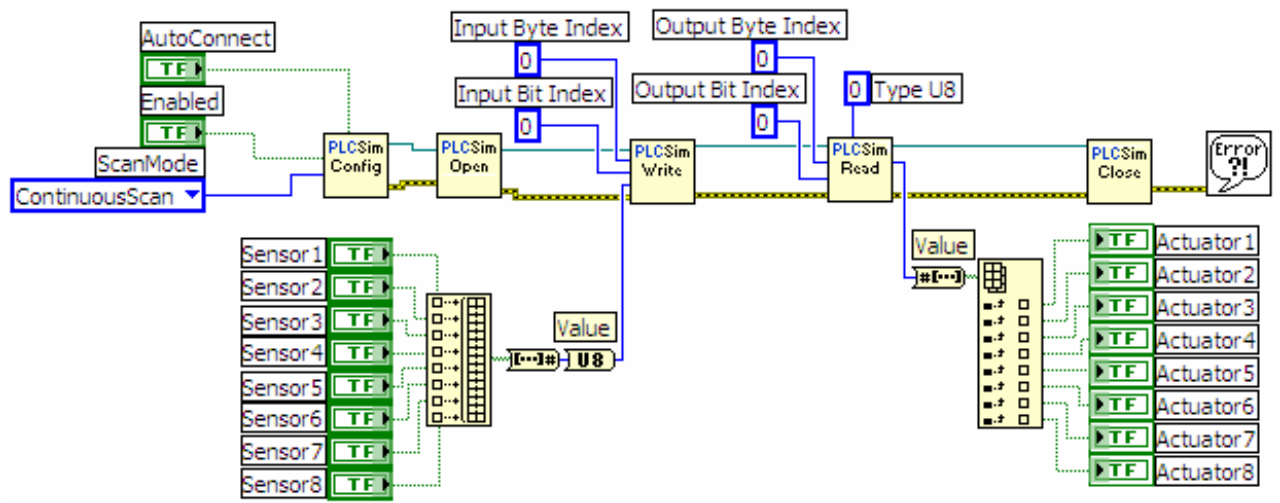

Fig. 7. Typical PLCSim connection

It is also possible to create new libraries that work with PLC environments from different providers, as long as the ActiveX technology is supported. It would be enough to select the adequate ActiveX Control and continue the scheme followed until now.

\section{Student's perception}

A survey was applied to all the students currently working with the Emulations, with the intention of knowing their perception about them. The students could rank each affirmation in a scale from 1 to 5 ; being 5 the highest score (Excellent) and 1 the worst score (Bad).

The obtained results (see Figure 8) show that a $77 \%$ of the students think that the Emulations help them in an excellent way (score 5) to solve all of their assignments, whereas the remaining $23 \%$ say that they did it in a very good way (score 4 ). An $84 \%$ of the students believe that the Emulations support the learning process at the laboratory in an excellent way (score 5), whereas the remaining $16 \%$ think that they did it in a very good way (score 4 ). An $84 \%$ of the students believe that the Emulations helped them to understand the concepts taught in class in an excellent way (score 5), whereas the remaining 16\% think that they did it in a very good way (score 4 ).

Finally, a $65 \%$ of the students believe that, in general, the use of the Emulations on Automation Laboratories is Excellent, whereas the remaining $35 \%$ think that it is Very Good.

It is important to emphasize that all of the results from the survey presented an Excellent (5) and Very Good (4) score; none of them received a score of 3 or less points. 


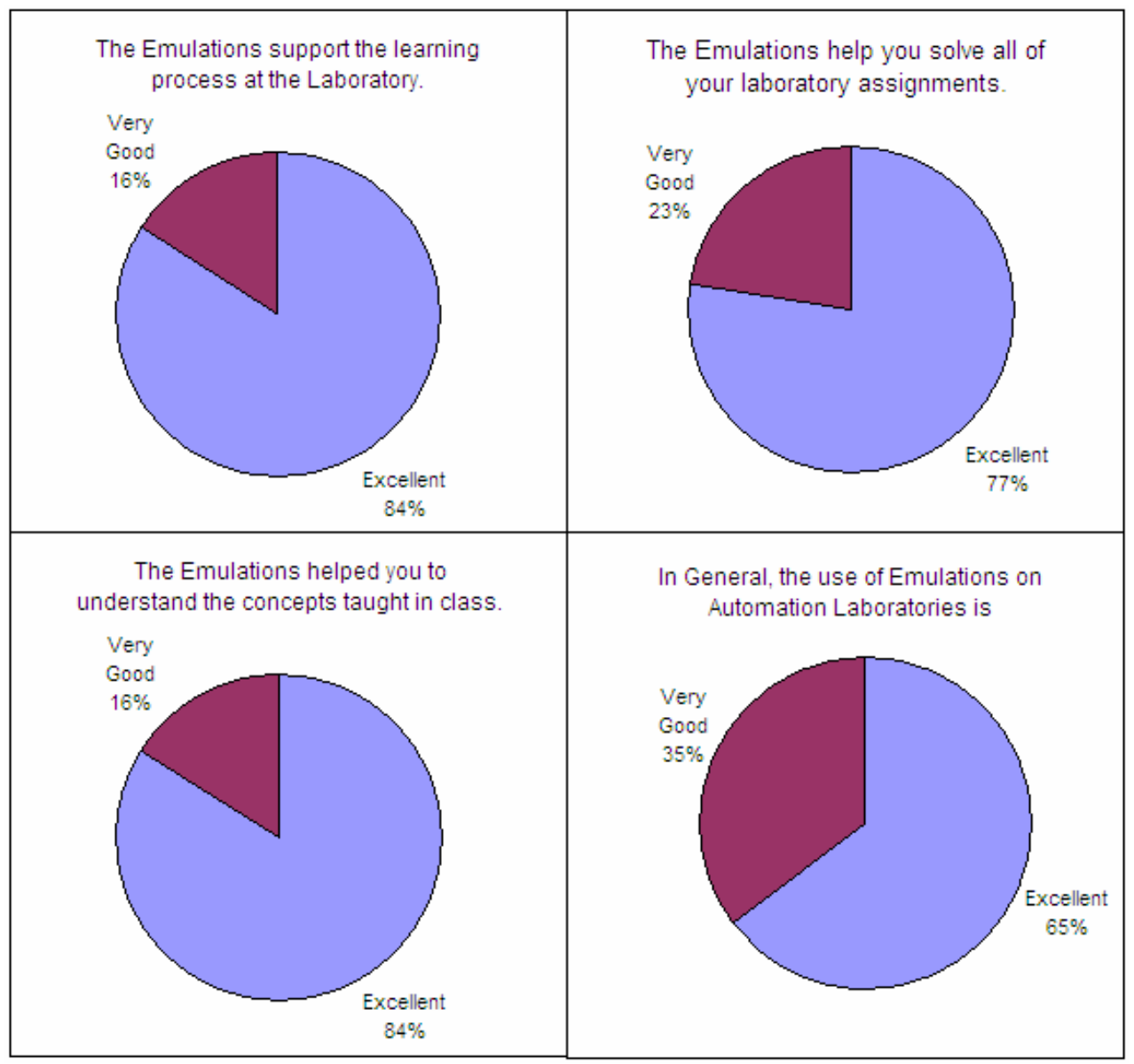

Fig. 8. Survey Results

\section{Conclusions}

Because of the high costs for appropriate laboratory equipment, one possible solution is to use computer emulations to support practical education and training.

In comparison with similar existing simulation software on the market, the referred computer emulations can be limitlessly distributed without restrictions and without having to purchase any license.

By handing the emulations to the students, the laboratory concept is extended. The students are then able to program, test, and debug their PLC programs without being restricted to a laboratory session. The laboratory is therefore always available.

The results obtained have shown that the students perform much better than in a traditional laboratory session. This fact has been confirmed after 3 years of using the Emulations as a part of the Tele-Engineering Lab at Monterrey Tech. The process has shown that the most important benefits are: 
- Students solve the exercises in a more enthusiastic way, which influences directly on their performance.

- Students accepted working with Emulations and they are even pleased with its use, because of the fact that they offer them more flexibility when solving their assignments.

- Students enhance their learning process and as a result they also increase their final grades.

- Instructors have said that it is much easier to review all of the exercises, since they can make different tests to a student's program.

\section{References}

[1] Fernández, Vicente, and Jiménez, Virtual Laboratories for Control Education: a Combined Methodology, Int. J. Engng Ed., Vol. 21, No. 6, pp. 1059-1067, 2005

[2] Liu, J., and Landers, R. G., Modular Control Laboratory System with Integrated Simulation, Animation, Emulation and Experimental Components, Int. J. Engng Ed., Vol. 21, No. 6, pp. 1005-1016, 2005

[3] Szczerbicka, Banks, Rogers, and Zeigler, "Conceptions of Curriculum for Simulation Education (Panel)", Proceedings of the 2000 Winter Simulation Conference, 2000.

[4] Größler, A., "Don't let history repeat itself--methodological issues concerning the use of Simulators in teaching and experimentation", System Dynamics Review ABI/INFORM, Vol. 20, No. 3, 2004, pp. 263.

[5] Macías, M., Méndez, I., TeleLab - Remote Automations Lab in Real Time, $38^{\text {th }}$ ASEE/IEEE Frontiers in Education Conference, 2008

[6] Kezunovic, M., Abur, A., Huang, G., Bose A. and Tomsovic, K., “The Role of Digital Modeling and Simulation in Power Engineering Education", IEEE transactions on power systems, Vol. 19, No. 1, 2004 pp. 64-72.

[7] Luo, W., Stravers, J., A., Duffin, K., L., "Lessons Learned from Using a Web-based Interactive Landform Simulation Model (WILSIM) in a General Education Physical Geography Course", Journal of Geoscience Education, Bellingham, Vol.53, No. 5, 2005, pp. 489.

[8] Debevec, K., Shih, Kashyap, V., "Learning Strategies and Performance in a Technology Integrated Classroom", Journal of Research on Technology in Education, Vol.38, No. 3, 2006, pp. 293.

[9] Macías, Méndez, Guridi, and Ortiz, TeleLab, Remote Laboratory for Automation and Control, IFAC Conference on Cost Effective Automation IFAC-CEA 2007.

[10] Gomis, Montesinos, Galceran, Bergas and Sudriá, "A Chemical Process Automation Virtual Laboratory to Teach PLC Programming", Int. J. Engng Ed., Vol. 23, No. 2, pp. 403-410, 2007

[11] Rodríguez, Berenguel, and Guzmán, “A Virtual Course on Automation of Agriculture Systems", Int. J. Engng Ed., Vol. 22, No. 6, pp. 1197-4101210, 2006 


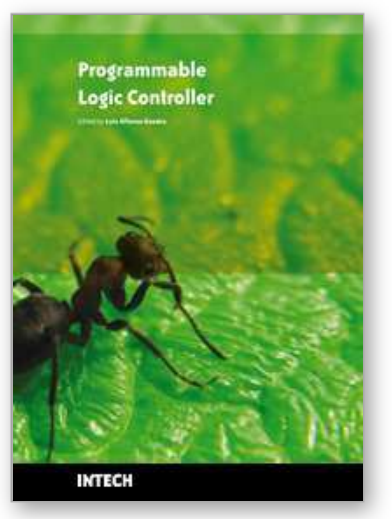

\author{
Programmable Logic Controller \\ Edited by Luiz Affonso Guedes
}

ISBN 978-953-7619-63-3

Hard cover, 170 pages

Publisher InTech

Published online 01, January, 2010

Published in print edition January, 2010

Despite the great technological advancement experienced in recent years, Programmable Logic Controllers (PLC) are still used in many applications from the real world and still play a central role in infrastructure of industrial automation. PLC operate in the factory-floor level and are responsible typically for implementing logical control, regulatory control strategies, such as PID and fuzzy-based algorithms, and safety logics. Usually PLC are interconnected with the supervision level through communication network, such as Ethernet networks, in order to work in an integrated form. In this context, this book was written by professionals that work and research in automation area and it has two major objectives. The first objective is present some advances in methodologies and techniques for development of industrial programs based on PLC. The second objective is present some PLC-based real applications from various areas such as manufacturing system, robotics, power system, communication system, and education.

\title{
How to reference
}

In order to correctly reference this scholarly work, feel free to copy and paste the following:

Manuel E. Macías and Ernesto D. Guridi (2010). Computer Emulations to Support Training in Automation, Programmable Logic Controller, Luiz Affonso Guedes (Ed.), ISBN: 978-953-7619-63-3, InTech, Available from: http://www.intechopen.com/books/programmable-logic-controller/computer-emulations-to-support-training-inautomation

\section{INTECH}

open science | open minds

\author{
InTech Europe \\ University Campus STeP Ri \\ Slavka Krautzeka 83/A \\ 51000 Rijeka, Croatia \\ Phone: +385 (51) 770447 \\ Fax: +385 (51) 686166 \\ www.intechopen.com
}

\author{
InTech China \\ Unit 405, Office Block, Hotel Equatorial Shanghai \\ No.65, Yan An Road (West), Shanghai, 200040, China \\ 中国上海市延安西路65号上海国际贵都大饭店办公楼 405 单元 \\ Phone: +86-21-62489820 \\ Fax: $+86-21-62489821$
}


(C) 2010 The Author(s). Licensee IntechOpen. This chapter is distributed under the terms of the Creative Commons Attribution-NonCommercialShareAlike-3.0 License, which permits use, distribution and reproduction for non-commercial purposes, provided the original is properly cited and derivative works building on this content are distributed under the same license. 